\title{
Turning cigarette butt waste into an alternative control tool against an insecticide-resistant mosquito vector
}

\author{
Hamady Dieng a,*, Sudha Rajasaygar a , Abu Hassan Ahmad a , Hamdan Ahmad a, \\ Che Salmah Md. Rawi ${ }^{\mathrm{a}}$, Wan Fatma Zuharah ${ }^{\mathrm{a}}$, Tomomitsu Satho ${ }^{\mathrm{b}}$, Fumio Miake ${ }^{\mathrm{b}}$, \\ Yuki Fukumitsu ${ }^{\mathrm{b}}$, Ahmad Ramli Saad ${ }^{\mathrm{a}}$, Idris Abd Ghani ${ }^{\mathrm{c}}$, Ronald Enrique Morales Vargas ${ }^{\mathrm{d}}$, \\ Abdul Hafiz Ab Majid ${ }^{a}$, Sazaly AbuBakar ${ }^{\mathrm{e}}$
}

a School of Biological Sciences, Universiti Sains Malaysia, Penang, Malaysia

${ }^{b}$ Faculty of Pharmaceutical Sciences, Fukuoka University, Japan

${ }^{c}$ Faculty of Science and Technology, Universiti Kebangsaan Malaysia, Kuala Lumpur, Malaysia

d Department of Medical Entomology, Faculty of Tropical, Medicine, Mahidol University, Thailand

e Department of Medical Microbiology, University of Malaya, Kuala Lumpur, Malaysia

\section{A R T I C L E I N F O}

\section{Article history:}

Received 9 August 2013

Accepted 19 August 2013

Available online 30 August 2013

\section{Keywords:}

Cigarette butt

Toxicity

Aedes aegypti

Larval development

\begin{abstract}
A B S T R A C T
Annually, 4.5 trillion cigarette butts (CBs) are flicked into our environment. Evidence exists that CB waste is deadly to aquatic life, but their lethality to the aquatic life of the main dengue vector is unknown. CBs are full of toxicants that occur naturally, during planting and manufacturing, which may act as larvicidal agents. We assessed Aedes aegypti vulnerability to Marlboro butts during its development. Overall, CBs showed insecticidal activities against larvae. At early phases of development, mortality rates were much higher in two CBs solution (2CBSol) and 3CBSol microcosms (MICRs). Larval survival gradually decreased with development in 1CBSol-MICRs. However, in great presence of CBs, mortality was high even for the late developmental stages. These results suggest that $A$. aegypti larvae are vulnerable to $C B$ presence in their habitats, but this effect was seen most during the early developmental phases and in the presence of increased amounts of cigarette remnants. CB filters are being used as raw material in many sectors, i.e., brick, art, fashion, plastic industries, as a practical solution to the pollution problem, the observed butt waste toxicity to mosquito larvae open new avenues for the identification of novel insecticide products.
\end{abstract} (c) 2013 Published by Elsevier B.V.

\section{Introduction}

Cigarette butt waste (CBW) represents a growing global environmental burden with an estimated 4.5 trillion discarded annually, with potential for further increases referring to a prediction (Mackay et al., 2006)-nine trillion expected by 2025. The environmental impact of CBW is related to their chemical composition-over 4000 different chemicals (Slaughter et al., 2011) and their persistence in the environment and potential toxic effects (Lee, 2012). Most of these chemicals are toxic and often leach into aquatic ecosystems, thereby threatening water supply sources and aquatic animals (Novotny et al., 2009, 2011) such as water fleas (Register, 2000), which inhabit freshwater environments, as do mosquito larvae (Dieng et al., 2011).

Mosquito-transmitted illnesses have become a major threat to global public health worldwide (Sarkar, 2010). In 2012, dengue was ranks as the most important mosquito-borne viral disease in the

\footnotetext{
* Corresponding author. Tel.: +60 103887158.

E-mail address: hamachan1@yahoo.com (H. Dieng).
}

world and as a pandemic threat (Portillo, 2013; WHO, 2013). The World Health Organization estimates that there may be $50-100$ million dengue infections worldwide every year, and more than 2.5 billion people-over $40 \%$ of the world's population-are now at risk (WHO, 2012a). The disease is now endemic in more than 100 countries (Simmons et al., 2012) including Malaysia (Tan et al., 2012). In recent years, the incidence of dengue in this country has increased markedly-from 30,110 cases with 69 deaths up to September 5, 2009 (MOH, 2009), the impact of this disease has reached 35,533 cases resulting in 107 deaths one year later (WHO, 2010). The northern part of the country, notably the State of Penang, has experienced a sharp spike in dengue transmission, recording about $60 \%$ of the total number of cases registered during the first 6 months of 2009 (Filmer and Ngo, 2010).

In this country, the prevalence of smoking has risen dramatically in recent years - from $21.5 \%$ in 2006 (Lim et al., 2009), the number of smokers has reached 40\% among men in 2012 (WHO, 2012b). Cigarette smoking has become a leading cause of illness and death - 10,000 Malaysian deaths are attributed to smokingrelated diseases annually (Fathelrahman et al., 2010). Therefore, in recent years, much effort has been directed toward correcting 